\title{
Effects of Clopidogrel and Low-Molecular-Weight Heparin on Viability of Random Skin Flaps in Rats
}

\author{
Fabio Antonio Vieira, MD ${ }^{1}$ Marcela Fernandes, MD, $\mathrm{PhD}^{1}$ Sandra Gomes Valente, $\mathrm{PhD}^{1}$ \\ Luis Renato Nakachima, MD, $\mathrm{PhD}^{1}$ Carlos Henrique Fernandes, MD, PhD ${ }^{1}$ \\ João Baptista Gomes Dos Santos, MD, PhD ${ }^{1}$
}

${ }^{1}$ Division of Hand and Upper Limb Surgery, Department of Orthopedics and Traumatology, Universidade Federal de São Paulo, São Paulo, Brazil

\begin{abstract}
Address for correspondence Fabio Antonio Vieira, MD, Division of Hand and Upper Limb Surgery, Department of Orthopedics and Traumatology, Universidade Federal de São Paulo, São Paulo, Brazil (e-mail: fabioavepm74@gmail.com).
\end{abstract}

J Reconstr Microsurg Open 2016;1:106-110.

\begin{abstract}
Keywords

- anticoagulants

- flap viability

- clopidogrel

- heparin

Background The viability of skin flaps is critical and greatly affects patient's quality of life. Effects of anticoagulant use on focal skin flap necrosis were explored, administering clopidogrel or low-molecular-weight heparin (LMWH) singly and in combination.

Methods Adult male rats $(N=40)$ were randomly assigned to one of four equally divided groups, raising a random dorsal flap $(10 \times 4 \mathrm{~cm})$ on each animal and delivering either no drug (control group) or daily applications of LMWH $(4 \mathrm{mg} / \mathrm{kg}$ ), clopidogrel (20 $\mathrm{mg} / \mathrm{kg}$ ), or both agents (LMWH-Clop) for a 7-day period. Thereafter, area and the percentage of flap necrosis (NP) were individually determined.

Results Average NP values were as follows: controls, 51.61\%; LMWH, 49.50\%; clopidogrel, 27.70\%; and LMWH-Clop, 29.71\%.

Conclusion Clopidogrel significantly enhanced the viability of random skin flap in rats, whereas single-agent LMWH or its combined usage conferred no significant benefits in this setting.
\end{abstract}

The transfer of tissue via skin flap, which generally remains connected (via pedicle) to the donor area, is widely used in all areas of reconstructive surgery to close cutaneous defects. ${ }^{1-3}$ However, flap necrosis is still a threat, with serious consequences for the patient. Several publications are now devoted to techniques for enhancing flap viability.

Flap necrosis may be intrinsic or extrinsic in nature. Although systemic conditions (infection, arteriosclerosis, hypotension, and malnutrition) and local dynamics (compression, tension, and pedicle twists) are among the many extrinsic influences, inadequate circulation is the only known intrinsic factor. ${ }^{4,5}$ Hence, any means of improving arterial supply and venous flow to prevent ischemic necrosis and promote surgical success are welcomed adjuncts.

Several studies have confirmed that the blood supply to tissues is improved by anticoagulants. Heparin, aspirin, and clopidogrel are the most common agents in this regard. Lowmolecular-weight heparins (LMWHs) are a new class of synthetic anticoagulants that are often used to treat ischemic heart disease and myocardial infarction or to serve as thromboembolic prophylaxis in various surgical contexts. LMWHs bind to and potentiate antithrombin III, specifically inhibiting factor Xa in the coagulation cascade. Other anticoagulants, including standard heparin, are less precise, binding various clotting factors. $^{6-8}$

According to the literature, use of heparin to salvage ischemic pedicles has met with inconsistent results. Intravenous heparin at various doses in a rabbit model significantly improved pedicle circulation and survival, even if administered 6 hours after surgery. ${ }^{7}$ However, a constant infusion of heparin failed to improve survival of random flaps in a pig model. ${ }^{9}$ Other related studies include work by Shalom et al, ${ }^{10}$ received

July 29, 2016

accepted after revision

August 8, 2016

published online

September 27, 2016
DOI http://dx.doi.org/

$10.1055 / \mathrm{s}-0036-1593403$.

ISSN $2377-0813$.
Copyright $\odot 2016$ by Thieme Medical

Publishers, Inc., 333 Seventh Avenue,

New York, NY 10001, USA.

Tel: +1(212) 584-4662.
License terms

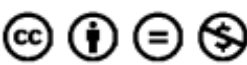


demonstrating no benefit from heparin in terms of flap survival, and a lack of prophylactic efficacy cited by Bielecki et al. $^{11}$ On the other hand, use of subcutaneous LMWH reportedly enhanced flap survival in an animal model developed by Miyawaki et $\mathrm{al}^{6}{ }^{6}$ and Törkvist et $\mathrm{al}^{8}$ determined that heparin at clinical dosages markedly improved rat skin flap viability.

Clopidogrel is a thienopyridine derivative prodrug that inhibits platelet aggregation. Hepatic cytochrome P450 and the P2C19 enzyme are required to generate its bioactive metabolite, which irreversibly blocks platelet adenosine diphosphate (ADP) receptors. Much of the clopidogrel dosage is completely degraded, leaving only a small portion for hepatic metabolism into its active moiety. ${ }^{12}$ Peak plasma concentration of metabolites occurs after 1 hour, and bioavailability is unaffected by the food intake. ${ }^{13}$

Use of clopidogrel has been shown to reduce both arterial and venous thrombi in animal models, and it is a key antiplatelet agent in patients with acute coronary syndrome who undergo percutaneous coronary intervention. Its benefits in the peripheral circulatory system and in cerebrovascular diseases are also evident. ${ }^{14}$ This study was performed to investigate the efficacy of clopidogrel and LMWH in improving skin flap survival, prompted by existing controversies and the relative shortage of publications addressing this issue.

\section{Methods}

This experimental study of interventional type was randomized, blinded, and controlled. Experimental procedures were performed in the Animal Collective Research Building I of the Federal University of São Paulo (UNIFESP-EPM). In total, 40 male Wistar-EPM rats were used, all adults weighing approximately 300 g each and supplied by the Center of Experimental Animal Models at Federal University of São Paulo (UNIFESP-EPM). Randomization was computer-driven (BioEstat 3.0 freeware), assigning animals to one of four equally divided groups (controls, LMWH, clopidogrel, and LMWH plus clopidogrel [LMWH-Clop]). The rats were caged individually, receiving commercial food and water ad libitum.

Anesthesia was achieved by intraperitoneal injection of ketamine hydrochloride and xylazine (1 IU/100 mg each) during both surgery and design/trichotomy of the flap area.

Dorsal flaps $(10 \times 4 \mathrm{~cm})$ were then raised, starting at the base of cranium and proceeding to lower angles of shoulder blades and upper hip bones as standard limits. ${ }^{15}$ Superficial fascia, panniculus carnosus, and skin were dissected in continuity from deep fascia and subsequently returned to original donor sites, ${ }^{16}$ leaving waterproof plastic barriers interposed. ${ }^{17}$ All flaps were sutured in place with simple 40 monofilament nylon sutures (-Fig. 1).

The control group was pharmacologically untreated. The three test groups received 7-day courses of either: once-daily subcutaneous LMWH (enoxaparin, $4 \mathrm{mg} / \mathrm{kg}$ ), starting immediately after surgery; once-daily oral clopidogrel $(20 \mathrm{mg} / \mathrm{kg}$ ) via physiological saline gavage ( $1 \mathrm{~mL}$ ), starting 6 hours before surgery; or both agents, as described above.

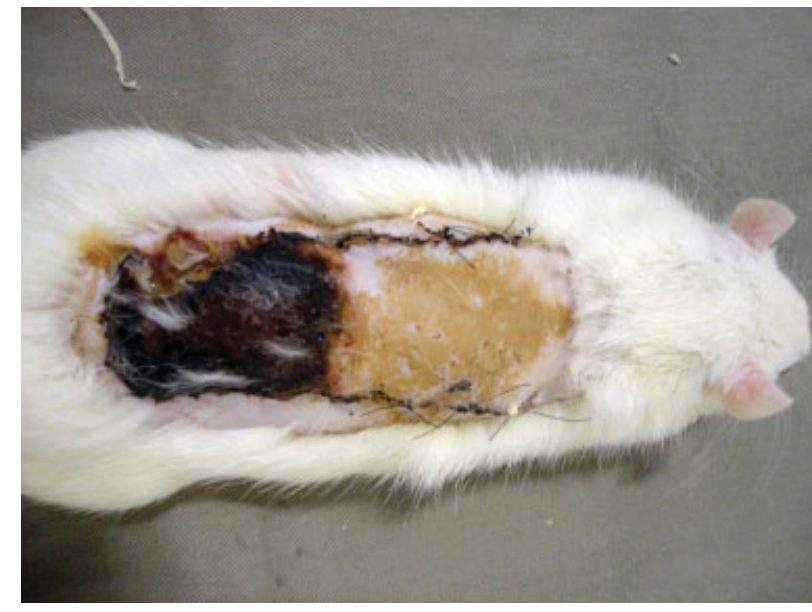

Fig. 1 The method of flap development.

Postoperatively, as analgesia, a single intravenous dose of tramadol hydrochloride ( $5 \mathrm{mg} / \mathrm{kg}$ ) was delivered immediately after surgery, and paracetamol (1-2 mg) was made available in the drinking water. Euthanasia by anesthetic overdose (ketamine hydrochloride and xylazine, 3 IU/100 mg each) took place on postoperative day 7 .

To quantify the percentage of flap necrosis (NP), the method of macroscopic analysis described by Sano et al ${ }^{18}$ was applied, using tracing paper, graphite $2 \mathrm{~B}$ pencils, and standard software (Photoshop CS2; Adobe Systems Inc., San Jose, CA). The rats were placed in prone position for overlayment by parchment paper (weight, 90-95 g/ $\mathrm{m}^{2}$; width, $6 \mathrm{~cm}$; length, $12 \mathrm{~cm}$ ). Researchers blinded to treatment groups traced entire flap contours and regions of necrosis. The soft, pink, warm, and hairy skin was considered viable. Necrotic skin was tight, darkened, cold, and hairless (-Fig. 2).

Areas outlined on parchment paper were scanned (300 dpi resolution) and quantified using computer software (ImageJ freeware). Macroscopic NP values were calculated as follows (-Fig. 3 and -Table 1):

Percentage of necrosis $=$ Area of flap necrosis / total area of flap $\times 100$

Total flap areas and areas of flap necrosis were recorded in Excel tables (Microsoft Office 2007; Microsoft Corp., Redmond, WA) for organization and formatting of data. Other software (BioEstat 4.0 freeware) was utilized for statistical analysis, applying Kruskal-Wallis analysis of variance to compare NP values of the four groups. Statistical significance was set at $p<0.05$, or $5 \%$.

\section{Results}

By nonparametric Kruskal-Wallis test, between-group differences in NP were statistically significant $(p=0.013)$; and using the Dunn test, both clopidogrel and LMWH-Clop test groups differed significantly from controls $(p<0.05)$. The LMWH test group and controls were similar, each differing significantly $(p<0.05)$ from the clopidogrel group in terms of 

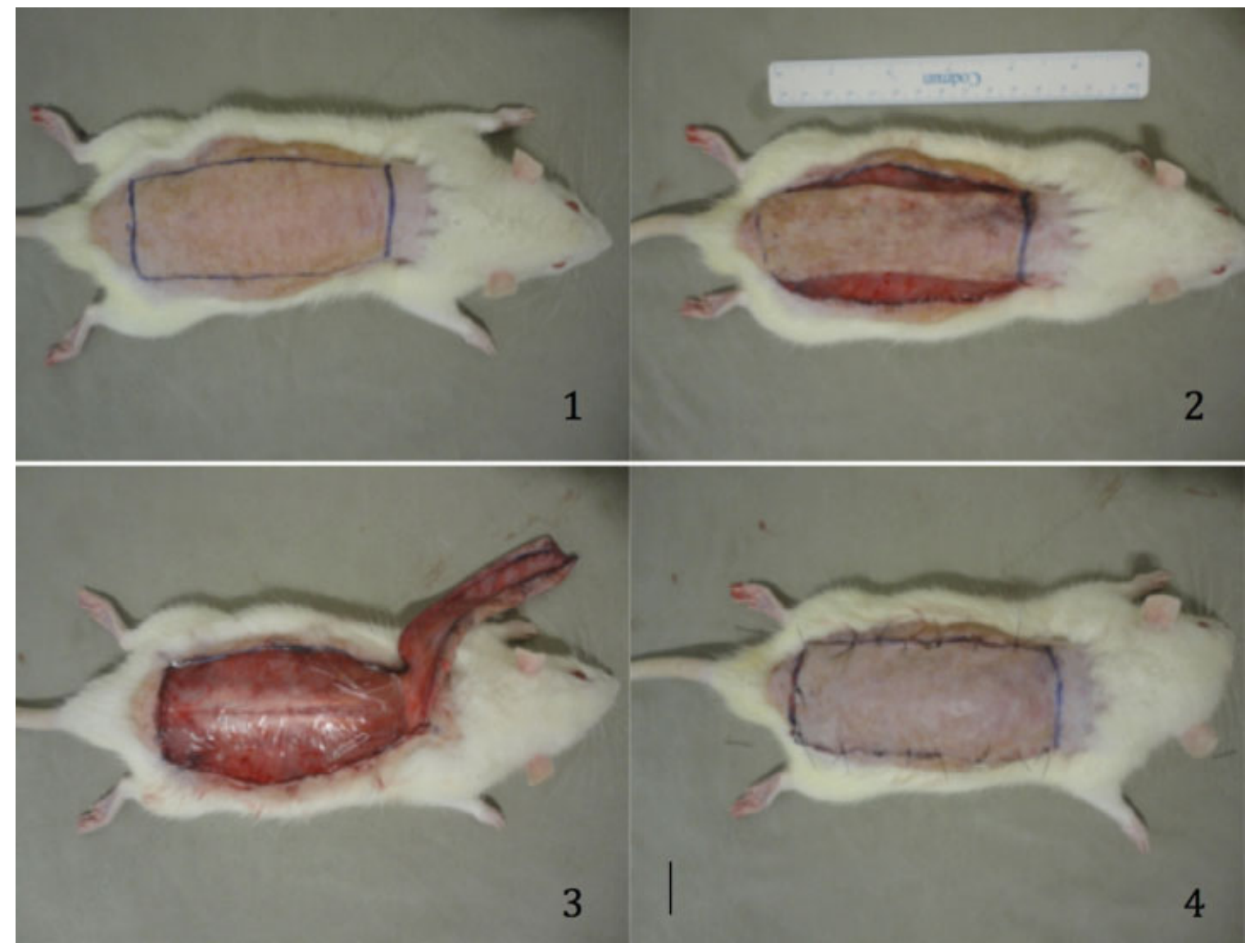

Fig. 2 Delineation of necrotic area (left).

$\mathrm{NP}$, whereas clopidogrel and LMWH-Clop test groups did not differ significantly.

\section{Discussion}

Necrosis of skin flaps remains a matter of great importance to reconstructive surgeons. A substantial number of publications have reported the use pharmacological or nonpharmacological strategies to improve skin flap viability. ${ }^{19}$ This study was intended to serve as a reference for future investigations, providing a contribution to restorative surgery and the scientific community in general.

The rat was chosen as our experimental model, based on availability, ease of handling, cost, and prior research (cited herein), although the animal most akin to humans is the pig.

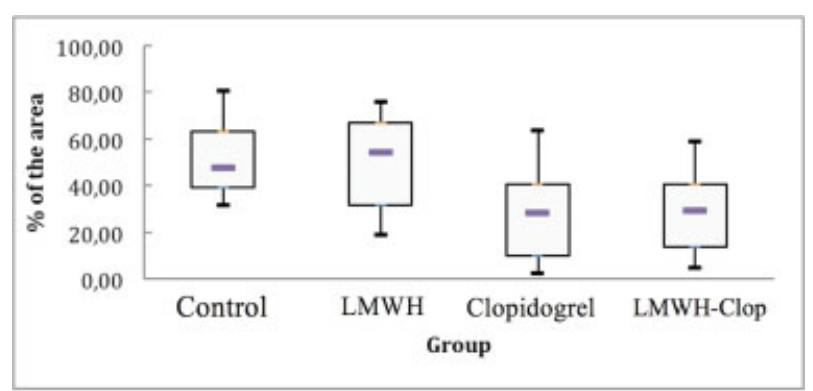

Fig. 3 Percentage of necrosis as group distributions.
Digital trichotomies were done to create hairless skin surfaces, which otherwise were unattainable by motorized appliance.

The dorsal random skin flap used in this study (attached at the base of the cranium) was proposed by McFarlane et al as an experimental model for study and prevention of necrosis. ${ }^{15}$ Such flaps $(10 \times 4 \mathrm{~cm})$ display considerable distal

Table 1 Percentage of necrosis by group (with averages)

\begin{tabular}{|l|l|l|l|l|}
\hline Rats & Control & LMWH & Clopidogrel & LMWH-Clop \\
\hline 1 & 59.37 & 66.76 & 11.45 & 25.73 \\
\hline 2 & 31.55 & 67.56 & 18.74 & 14.71 \\
\hline 3 & 41.32 & 52.26 & 38.49 & 11.17 \\
\hline 4 & 32.96 & 21.4 & 5.01 & 35.03 \\
\hline 5 & 58.57 & 75.79 & 38.28 & 23.75 \\
\hline 6 & 50.45 & 19.14 & 41.12 & 52.97 \\
\hline 7 & 80.69 & 58.09 & 17.27 & 33.34 \\
\hline 8 & 44.84 & 56.55 & 63.53 & 58.96 \\
\hline 9 & 75.2 & 34.91 & 40.66 & 4.73 \\
\hline 10 & 41.11 & 42.56 & 2.49 & 36.73 \\
\hline Average & 51.61 & 49.50 & 27.70 & 29.71 \\
\hline
\end{tabular}

Abbreviations: LMWH, low-molecular-weight heparin; LMWH-Clop, combination of low-molecular-weight heparin and clopidogrel. 
necrosis (average, 25-50\%) and rarely are free of significant necrosis (5.7\%). To promote more extensive and homogeneous necrosis, a waterproof plastic barrier was interposed between each flap and donor site, thus precluding donor-site revascularization. ${ }^{17,20}$ The doses and treatment duration were chosen based on previous studies on this subject, to obtain a better comparison. . $^{21,22}$

The pathophysiology of necrosis due to ischemia is complex, involving vascular insufficiency as a consequence of arterial vasospasm mediated by vasoactive substances, production of free radicals, swelling of endothelial cells, inactivation of sodium and potassium pumps, and thrombotic venous congestion. ${ }^{4,23}$ Two important mechanisms have been implicated in postsurgical damage: neutrophilic influx and vascular thrombosis. ${ }^{10}$ Platelets are pivotal in vascular thrombosis, as is venous blood flow. Exposed subendothelial matrix and factors releasing prothrombin result in activation and adhesion of platelets at the onset of thrombus formation. ${ }^{14}$ Fundamentally, venous thrombosis appears to instigate arterial occlusion and necrosis. ${ }^{6}$

Prevention of platelet aggregation is thus an important pharmacotherapeutic strategy for preventing flap necrosis. Heparin, aspirin, and clopidogrel all effectively in prevent vascular thrombosis, leading to improved circulation and flap survival. Enoxaparin inhibits the conversion of prothrombin to thrombin, thereby reducing thrombin-mediated clotting as fibrinogen is converted to fibrin. Enoxaparin has potent anticoagulant activity, with a lower propensity for bleeding than unfractionated heparin. ${ }^{21}$ Low-dose enoxaparin also exerts anti-inflammatory effects in animal models and in humans, so its therapeutic effects may be attributable to a combination of anticoagulant and anti-inflammatory properties. ${ }^{10}$ However, some researchers maintain that its anticoagulant activity is key, based on microcirculatory changes. ${ }^{21}$ Aral et al compared various pharmacological compounds, thrombolytic, anticoagulant, and vasodilator agents in rats and found significant improvement in the necrotic area only with the use of LMWH. ${ }^{24}$

Clopidogrel is a new antiplatelet prodrug that gained U. S. market approval in 1997. Its active metabolite, generated by the P2C19 hepatic cytochrome enzyme, irreversibly blocks platelet P2Y12 (ADP) receptors to inhibit platelet aggregation. $^{22}$ The high degree of individual variability observed is possibly due to erratic oral absorption, variable metabolism, unidentified active metabolites, and differing reactivity of ADP receptors. Evidence supports oral absorption as the main issue. ${ }^{12}$ Clopidogrel proved superior to aspirin in a comparative study of patients at risk of ischemic events, ${ }^{14}$ and its use significantly increased flap survival rates in another study, likely by preventing platelet aggregation, vasodilatation, and oxygen free radical release upon ischemic reperfusion. ${ }^{25}$

In examining the effects of LMWH on flap viability, there are many experimental and clinical studies presenting a broad range of positive and negative results. However, few experimental studies have evaluated clopidogrel and LMWH in combination for this purpose. ${ }^{25,26}$ The findings of Khouri et al suggest that heparin is critical in maintaining microanastomotic patency ${ }^{27}$, but electron microscopic analysis of thrombi by Savoie et al indicates that simultaneous dualagent use produces better clinical results through joint inhibition of fibrin formation and platelet aggregation. ${ }^{28}$ Unfortunately, the most important related complication, namely, an increased risk of bleeding (especially in the gastrointestinal tract), is heightened by combination therapy.

In the study conducted by Fatemi et $\mathrm{al}^{29}$ there was no significant improvement in necrosis when LMWH-Clop was used. Unlike Fatemi et al, our study showed a lower area of flap necrosis with the use of clopidogrel (40-28\%) and a significant improvement $(p<0.05)$ when used in combination therapy, demonstrating that the use of heparin does not negate the benefit found by clopidogrel.

In this investigation, use of clopidogrel significantly increased flap survival in rats, reducing necrosis to $27.7 \%$ on average. The latter is aligned with other reported studies of clopidogrel, citing 22 to $40 \%$ necrosis. ${ }^{26,29}$ Although LMWH marginally reduced average flap necrosis, compared with controls (49.50 vs. 51.61\%), the difference was not significant. To date, use of LMWH in this setting has been inconsistent, some studies demonstrating benefits ${ }^{23,30}$ and others showing a lack of significant improvement (42-48\% necrosis) in flap viability as observed here. ${ }^{20,29}$

Our combined use of drugs produced a significant improvement in average flap necrosis, compared with controls (29.71 vs. $51.61 \%$ ), although the effect was similar to that achieved with single-agent clopidogrel. Despite the apparent advantages of LMWH-Clop, as documented by Savoie et al, ${ }^{28}$ combination therapy in our animal model conferred no real benefit.

\section{Conclusion}

Clopidogrel proved superior to LMWH, demonstrating significant improvement $(p<0.05)$ in experimental skin flap viability when used as monotherapy. No added value was contributed by combining the two drugs.

\section{References}

1 Abla LEF, Gomes HC, Percario S, Ferreira LM. Acetylcysteine in random skin flap in rats. Acta Cir Bras 2005;20(2):121-123

2 Duarte IdS, Gomes HFdC, Ferreira LM. Effect of dimethyl sulphoxide on necrosis of skin flaps in rats. Can J Plast Surg 1998;6(2):93-97

3 Sasaki GH, Pang CY. Hemodynamics and viability of acute neurovascular island skin flaps in rats. Plast Reconstr Surg 1980;65(2): 152-158

4 Kerrigan CL, Stotland MA. Ischemia reperfusion injury: a review. Microsurgery 1993;14(3):165-175

5 Russell RC, Roth AC, Kucan JO, Zook EG. Reperfusion injury and oxygen free radicals: a review. J Reconstr Microsurg 1989;5(1): $79-84$

6 Miyawaki T, Jackson IT, Elmazar H, et al. The effect of lowmolecular-weight heparin in the survival of a rabbit congested skin flap. Plast Reconstr Surg 2002;109(6):1994-1999

7 Sawhney CP. The role of heparin in restoring the blood supply in ischaemic skin flaps: an experimental study in rabbits. Br J Plast Surg 1980;33(4):430-433

8 Törkvist L, Löfberg R, Raud J, Thorlacius H. Heparin protects against skin flap necrosis: relationship to neutrophil recruitment and anti-coagulant activity. Inflamm Res 2004;53(1):1-3 
9 Wray RC Jr, Young VL. Drug treatment and flap survival. Plast Reconstr Surg 1984;73(6):939-942

10 Shalom A, Friedman T, Westreich M. Effect of aspirin and heparin on random skin flap survival in rats. Dermatol Surg 2008;34(6): 785-790, discussion 790

11 Bielecki M, Karpik M, Skowroński J. The effect of prophylactic doses of nadroparin and therapeutic doses of betamethasone on skin flap survival in rats. Folia Histochem Cytobiol 2009; 47:673-677

12 Maree AO, Fitzgerald DJ. Variable platelet response to aspirin and clopidogrel in atherothrombotic disease. Circulation 2007; 115(16):2196-2207

13 Roden DM, Shuldiner AR. Responding to the clopidogrel warning by the US food and drug administration: real life is complicated. Circulation 2010;122(5):445-448

14 Gurbel PA, Tantry US. Combination antithrombotic therapies. Circulation 2010;121(4):569-583

15 McFarlane RM, Deyoung G, Henry RA. The design of pedicle flap in the rat to study necrosis and its preventions. Plast Reconstr Surg 1965;35:177-182

16 Gomes HC, Bueno PCS, Scardoeli CAC, Percario S, Landman MRL, Ferreira LM. Effect of n-acetylcysteine in a random skin flap after administration of nicotine in the rat. FMED 1998;117:209-211

17 Körlof B, Ugland O. Flaps and flap necrosis. Improving the circulation in skin flaps with Complamin and with Dicoumarol: animal experiments. Acta Chir Scand 1966;131(5):408-412

18 Sano K, Hallock GG, Wasser TE, Robson PA, Rice DC. Comparison of a new method for computer analysis with standard techniques for measuring survival rates in the rat transverse rectus abdominis musculocutaneous flap. Ann Plast Surg 2001;47(6): 647-651

19 Liebano RE, Ferreira LM, Sabino Neto M. Transcutaneous electrical nerve stimulation on viability of random skin flap in rats. Can J Plast Surg 2002;10:151-154
20 Kaufman T, Angel MF, Eichenlaub EH, Levin M, Hurwitz DJ, Futrell JW. The salutary effects of the bed on the survival of experimental flaps. Ann Plast Surg 1985;14(1):64-73

21 Ertas NM, Goldman C, Deitcher S, Siemionow M. Dose response of enoxaparin at the cremaster muscle flap microcirculation. Microsurgery 2005;25(2):147-151

22 O'Donoghue M, Wiviott SD. Clopidogrel response variability and future therapies: clopidogrel: does one size fit all? Circulation 2006;114(22):e600-e606

23 Atalay C, Koçkaya EA, Çetin B, Kismet K, Akay MT. Efficacy of topical nitroglycerin and transcutaneous electrical nerve stimulation on survival of random-pattern skin flaps in rats. Scand J Plast Reconstr Surg Hand Surg 2003;37(1):10-13

24 Aral M, Tuncer S, Şencan A, Elmas Ç, Ayhan S. The Effect of Thrombolytic, Anticoagulant, and Vasodilator Agents on the Survival of Random Pattern Skin Flap. J Reconstr Microsurg 2015; 31(7):487-492

25 Akan M, Cakir B, Misirlioğlu A, Yildirim S, Taylan G, Aköz T. Effects of clopidogrel and high dose aspirin on survival of skin flaps in rats. Scand J Plast Reconstr Surg Hand Surg 2005;39(1):7-10

26 Ersoy A, Sevin K, Sevin A, Serel S. Effects of clopidogrel on survival of rat skin flaps. J Plast Reconstr Aesthet Surg 2007;60(8):861-863

27 Khouri RK, Cooley BC, Kunselman AR, et al. A prospective study of microvascular free-flap surgery and outcome. Plast Reconstr Surg 1998;102(3):711-721

28 Savoie FH, Cooley BC, Gould JS. Evaluation of the effect of pharmacologic agents on crush-avulsion arterial injuries: a scanning electron microscopy study. Microsurgery 1991;12(4):292-300

29 Fatemi MJ, S. Forootan K, S. Jalali SZ, Mousavi SJ, Pedram MS. The effect of enoxaparin and clopidogrel on survival of random skin flap in rat animal model. World J Plast Surg 2012;1(2):64-70

30 Chung TL, Holton LH III, Silverman RP. The effect of fondaparinux versus enoxaparin in the survival of a congested skin flap in a rabbit model. Ann Plast Surg 2006;56(3):312-315 